\title{
Pediatric Head Injury: The Incidence of Multiple Injuries
}

\author{
Thomas Kapapa ${ }^{*}$, Melanie Kapapa ${ }^{2}$, Carsten Posovszky ${ }^{3}$, Joachim Gülke ${ }^{4}$, Ralph König1, \\ Dieter Woischneck ${ }^{5}$ Christian Rainer Wirtz ${ }^{1}$, Andrej Pala ${ }^{1}$ \\ ${ }^{1}$ Neurochirurgische Klinik, Universitätsklinikum UIm, Ulm, Germany \\ ${ }^{2}$ Sektion Kinderchirurgie, Universitätsklinikum UIm, Ulm, Germany \\ ${ }^{3}$ Klinik für Kinder-und Jugendmedizin, Universitätsklinikum Ulm, Ulm, Germany \\ ${ }^{4}$ Klinik für Unfall-, Hand-und Plastische und Wiederherstellungschirurgie, Universitätsklinikum UIm, UIm, \\ Germany \\ ${ }^{5}$ Neurochirurgische Klinik, Klinikum Landshut, Landshut, Germany \\ Email: *Thomas.Kapapa@uniklinik-ulm.de
}

Received 5 January 2016; accepted 4 June 2016; published 8 June 2016

Copyright (C) 2016 by authors and Scientific Research Publishing Inc.

This work is licensed under the Creative Commons Attribution International License (CC BY).

http://creativecommons.org/licenses/by/4.0/

c) (i) Open Access

\section{Abstract}

Objectives: Concomitant injuries play an important role when it comes to clinical management of traumatic brain injury (TBI). We examined the incidence of concomitant injuries and their relevance with respect to hospitalization. Methods: Children aged between 0 - 18 years hospitalized for treatment of TBI (ICD 10; S06.0 - 9) during 2010-2011 were included. The data relating to concomitant injuries and the course of treatment were evaluated. Statistical analysis included multivariate regressions at a level of significance of $p \leq 0.05$. Results: 794 children were treated for head injury in our hospital. Head injury with other associated injuries had been sustained by 158 $(19.9 \%)$ children. The face and the extremities were the areas of the body most often affected $(p=$ 0.001). Boys represent the majority within the cohort of multiple injured children $(p=0.0001)$. The older the child, the higher the percentage of children with concomitant injuries $(r=0.27 ; p=$ 0.034). There was a significant correlation between the severity of the head injury and the occurrence of concomitant injuries $(r=0.19 ; p=0.046)$. Children with concomitant injuries were found to suffer significantly more falls $(N=82 ; 51.9 \%)$ than road traffic accidents $(N=68 ; 43 \%)(p=$ 0.0001 ). A comparison of different variables revealed that age ( 7 to 10 years), severity of head injury (mild TBI), and trauma mechanism (fall) were most influential $(\mathrm{KB}=-1.55 ; \mathrm{p}=0.023$ ) for concomitant injuries. Children with concomitant injuries have a significant longer stay in hospital than those without: mean stay 2.5 to 4.5 days $(p=0.0001)$. Conclusion: Concomitant injuries are hints for more severe head injuries and children should be examined with special care.

${ }^{*}$ Corresponding author. 


\section{Keywords}

\section{Isolated Traumatic Brain Injury, Concomitant Injury, Facial Injury, Length of Hospitalization}

\section{Introduction}

Traumatic brain injury, especially mild brain injury, in children is common. However, given the variable levels of development of the motor system and balance, as well as mobility, the risk of traumatic brain injury in a developing child also varies. Epidemiological studies reveal that children, as a special age group, are exposed to different forces and exertions than adults. This is reflected simply by the fact that children are involved in fewer car accidents [1]. We find that children aged $1-4$ years, and in this particular instance boys, are especially at risk [2]. At such an age, falls from lower heights in the domestic environment, such as from furniture, are common. They are seldom associated with severe head or brain injuries [3]. Nevertheless, additive injuries in the event of a traumatic brain (TBI) injury are not uncommon.

The injury pattern in adult patients with multiple injuries and the influence of different injuries as well as their combination on a patient's prognosis, have already been studied in depth [4] [5]. However, only few publications address concomitant injuries in relation to traumatic brain injury in children [6]-[8]. Most of the studies addressed the extra-cranial injuries more than the intracranial injuries. Unlike adults, infants or babies already experience serious circulatory disturbances due to slight blood loss in other compartments, such as in the muscles when fracturing a tubular bone, or under the skin. In turn, disturbed blood flow can accentuate the secondary brain damage following traumatic brain injury [9]. Traumatic brain injury in a child with multiple injuries is an important factor when it comes to survival and treatment outcome [1] [10].

This study reflects the distribution and relevance of concomitant injuries in children experienced TBI in relation to age, sex, trauma mechanism and outcome. To the best of our knowledge, the overall connection to weekday and daytime is hereby described by the first time.

\section{Patients and Methods}

\subsection{Design}

This study was designed as descriptive-observational and conducted at a university medical hospital with a catchment population estimated at 170,000. The departments of neurosurgery, paediatrics, paediatric surgery and traumatology participated in the study.

\subsection{Inclusion Criteria}

All patients less than 19 years of age admitted with a diagnosis of head injury (ICD 10; S06.0-9) between 1 January 2010 and 31 December 2011 were included. Only symptomatic patients (vomiting, headache, paresis or disturbances of consciousness) or patients without symptoms but radiographic signs of intracranial trauma (ultrasound, computed tomography, magnet-resonance-imaging) were admitted for hospitalized treatment and included.

\subsection{Exclusion Criteria}

Patients with acute neurological deficits or symptoms like vomiting, headache, paresis or disturbances of consciousness without any context of acute traumatic brain injury and patients that were not admitted were excluded.

\subsection{Data}

Data were collected using standardized clinical notes which were entered in a database and evaluated. Data on the patient's sex, mechanism of injury, associated injuries, Glasgow Coma Score (GCS), length of hospital stay, neurosurgical procedures and outcome at discharge were documented [11]. The modified Glasgow Coma Scale (Frankfurter Glasgow Coma Scale $=$ fGCS) for Children and the Glasgow Coma Scale was used to grade the traumatic brain injuries and to classify the severity of the head injuries. Injuries were classified in children from 25 months of age on as severe (severe TBI) at a GCS score of 8 or less, moderate (moderate TBI) at a score of 
between 9 and 12, and mild (mild TBI) at a score of more than 12. The classification was adapted for children aged under 25 months: severe (severe TBI) at a fGCS score of 11 or less, moderate (moderate TBI) at a score of between 12 and 16, and mild (mild TBI) at a score of between 12 and 19 [2]. The outcome was defined as good at a score of $\geq 4$ on the Glasgow Outcome Scale and $\leq 2$ on the modified Rankin Scale, otherwise as unfavorable [12]-[15]. Concomitant injuries were assigned to 5 different body regions, namely head and neck, face, chest, abdomen or pelvic girdle, and extremities (Table 1) [16] [17].

We divided the population into 6 groups according to age, namely under 1 year, $1-4,5-6,7-10,11-14$, and $15-18$ years.

When testing for differences between smaller groups, the Kolmogorov-Smirnov, Kruskal-Wallis test and Wilcoxon/Mann-Whitney tests were used for non-parametric analysis. Otherwise the t-test, fisher-test, and the ANOVA were used. Correlations and regressions were performed by Spearmens' Test as well as Kendalls' tau (b and c) and univariate/multivariate regression analysis. We used SPSS ${ }^{\circledR}$ statistical software (IBM Company, SPSS Inc. Chicago Illinois) to analyze the collected data.

The local university ethic committee approved this study (Nr. 380/14).

\section{Results}

\subsection{Patients}

From 1 January 2010 to 31 December 2011, 794 children with head injuries were treated in our hospital (2010 N $=379,47.7 \% ; 2011 \mathrm{~N}=415,52.3 \%)$. The majority of children were between one and four years of age. The distribution of TBI across the different age groups is described in Table 2. A total of 487 of the patients were male (61.3\%), and in all groups boys were consistently more likely to sustain a head injury.

Mild TBI was noted in $765(96.3 \%)$ patients; 15 children (1.9\%) suffered moderate TBI and 14 children (1.8\%) severe TBI. The severity distribution across the age groups is described in Table 2.

\subsection{Incidence of Concomitant Injuries}

Isolated head trauma was noted in $636(80.1 \%)$ patients. Head injury with concomitant injuries were sustained by $158(19.9 \%)$ children $(80.1 \%$ without concomitant injuries: $p=0.0001)$. In $124(78.5 \%)$ cases only one other part of the body was injured (e.g. thorax or extremities). In 34 (21.5\%) cases concomitant injuries were sustained in more than one additional region of the body (e.g. thorax and extremities). The number of additional parts of the body suffering an injury totaled 200 (126.5\% of the children with additional injuries) (Table 3). A more precise breakdown of the injuries sustained, and regions involved, can be found in Table 3 .

\subsection{Sex}

Boys sustained significantly more concomitant injuries than girls $(\mathrm{p} \leq 0.016)$ (Figure 1$)$. The greatest difference in incidences of each part of the body was found in relation to facial injuries $(\Delta 19)$. With lower incidences boys sustain more abdominal injuries than girls $(\Delta 10)$.

\subsection{Age}

Age was found to correlate significantly to the incidence of concomitant injuries: the older the child, the higher

Table 1. Division of the body into five regions as per the Injury Severity Score and incidence of a total of 200 concomitant injuries in the entire study population of $\mathrm{N}=794$ children and 158 children with concomitant injuries.

\begin{tabular}{ccc}
\hline Region & Localisation & Incidence \\
\hline Head and Neck & Neck and cervical spine & $\mathrm{N}=67 ; 33.5 \%$ \\
Face & Facial injury & $\mathrm{N}=67 ; 33.5 \%$ \\
Chest & Chest, thorax, , diaphragm including thoracic spine & $\mathrm{N}=31 ; 15.5 \%$ \\
Abdomen or Pelvic Girdle & Abdomen, lesser and greater pelvis including lumbal spine & $\mathrm{N}=22 ; 11 \%$ \\
Extremities & Extremities with fractures and distension, luxation & $\mathrm{N}=13 ; 6.5 \%$ \\
Total & & \\
\hline
\end{tabular}


Table 2. Frequency characteristics of the population in terms of the incidence of concomitant injuries and classification according to sex, age, severity of traumatic brain injury, trauma mechanism and treatment outcome.

\begin{tabular}{|c|c|c|c|}
\hline & $\begin{array}{l}\text { No concomitant injuries } \\
(N=636,80.1 \%)\end{array}$ & $\begin{array}{l}\text { Concomitant injuries } \\
(\mathrm{N}=158,19.9 \%)\end{array}$ & $\begin{array}{c}\text { Total } \\
(794,100 \%)\end{array}$ \\
\hline \multicolumn{4}{|l|}{ Sex } \\
\hline Male & $390(80.1 \%)$ & $97(19.9 \%)$ & $487(61.3 \%)$ \\
\hline Female & $246(80.1 \%)$ & $61(19.9 \%)$ & $307(38.7 \%)$ \\
\hline \multicolumn{4}{|l|}{ TBI Grade } \\
\hline Mild TBI & $634(81.6 \%)$ & $141(18.4 \%)$ & $765(96.3 \%)$ \\
\hline Moderate TBI & $8(53 \% .3)$ & $7(46.7 \%)$ & $15(1.9 \%)$ \\
\hline Severe TBI & $4(28.6 \%)$ & $10(71.4 \%)$ & $14(1.8 \%)$ \\
\hline \multicolumn{4}{|l|}{ Age } \\
\hline Younger than 1 year & $118(91.5 \%)$ & $11(8.5 \%)$ & $129(16.2)$ \\
\hline 1 to 4 years & $288(87.8 \%)$ & $40(12.2 \%)$ & $328(41.3 \%)$ \\
\hline 5 to 6 years & $59(77.6 \%)$ & $17(22.4 \%)$ & $76(9.6 \%)$ \\
\hline 7 to 10 years & $83(72.2 \%)$ & $32(27.8 \%)$ & $115(14.5 \%)$ \\
\hline 11 to 14 years & $51(60 \%$ & $34(40 \%)$ & $85(10.7)$ \\
\hline 15 to 18 years & $37(60.7 \%)$ & $24(39.3 \%)$ & $61(7.7 \%)$ \\
\hline \multicolumn{4}{|l|}{ Mechanism } \\
\hline Fall & $533(86.7 \%)$ & $82(13.3 \%)$ & $615(77.5 \%)$ \\
\hline Traffic accident & $45(39.8 \%)$ & $68(60.2 \%)$ & $113(14.2 \%)$ \\
\hline other & $58(87.9 \%)$ & $8(12.1 \%)$ & $66(8.3 \%)$ \\
\hline \multicolumn{4}{|l|}{ Outcome } \\
\hline \multicolumn{4}{|l|}{ Modified Rankin Scale } \\
\hline 0 & $628(81.2 \%)$ & $145(18.8 \%)$ & $773(97.4 \%)$ \\
\hline 1 & $5(50 \%)$ & $5(50 \%)$ & $10(1.3 \%)$ \\
\hline 2 & $1(25 \%)$ & $3(75 \%)$ & $4(0.5 \%)$ \\
\hline 3 & $0(0 \%)$ & $3(100 \%)$ & $3(0.35 \%)$ \\
\hline 4 & $1(50 \%)$ & $1(50 \% 9$ & $2(0.25 \%)$ \\
\hline 5 & $1(100 \%)$ & $0(0 \%)$ & $1(0.1 \%)$ \\
\hline 6 & $0(0 \%)$ & $1(100 \%)$ & $1(0.1 \%)$ \\
\hline Unfavourable & $2(28.6 \%)$ & $5(71.4 \%)$ & $7(0.8 \%)$ \\
\hline Good & $634(80.6 \%)$ & $153(19.4 \%)$ & $787(99.2 \%)$ \\
\hline \multicolumn{4}{|l|}{ Glasgow Outcome Scale } \\
\hline 1 & $0(0 \%)$ & $1(100 \%)$ & $1(0.1 \%)$ \\
\hline 2 & $1(100 \%)$ & $0(0 \%)$ & $1(0.1 \%)$ \\
\hline 3 & $2(50 \%)$ & $2(50 \%)$ & $4(0.5 \%)$ \\
\hline 4 & $2(20 \%)$ & $8(80 \%)$ & $10(1.3 \%)$ \\
\hline 5 & $631(81.1 \%)$ & $147(18.9 \%)$ & $778(97.9 \%)$ \\
\hline Unfavourable & $3(50 \%)$ & $3(50 \%)$ & $6(0.8 \%)$ \\
\hline Good & $633(80.3 \%)$ & $155(19.7 \%)$ & $788(99.2 \%)$ \\
\hline
\end{tabular}




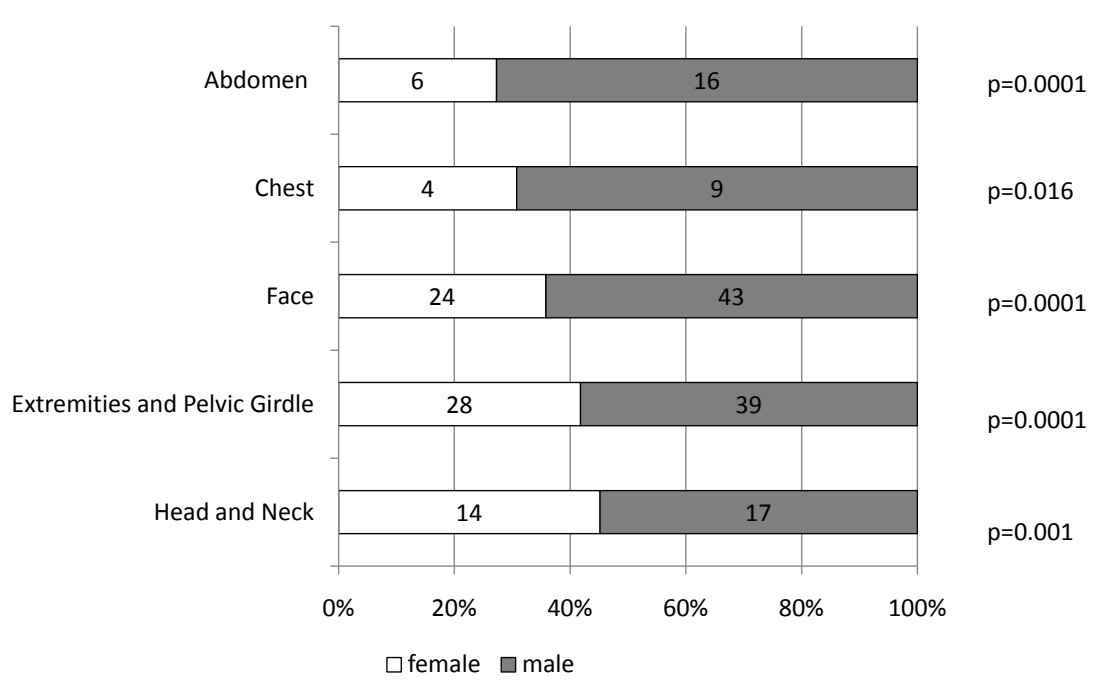

Figure 1. Presentation of sex-specific differences in the occurrence of injuries to other parts of the body.

Table 3. Additional breakdown of injuries by region of the body and incidence $(\mathrm{N})$.

\begin{tabular}{|c|c|c|c|c|c|}
\hline \multirow{2}{*}{$\begin{array}{c}\text { Head and Neck }(\mathbf{N}) \\
\text { cervical bruise/distortion }\end{array}$} & \multicolumn{3}{|c|}{ Chest (N) } & \multicolumn{2}{|c|}{ Extremities or Pelvic Girdle (N) } \\
\hline & 24 & Bruise or fractures of rips and/or Sternum & 10 & Knee bruise & 33 \\
\hline \multirow[t]{2}{*}{ cervical spine fracture } & 7 & & & Ellbow bruise & 10 \\
\hline & & Fracture of the thoracic spine & 2 & Tibia fracture & 9 \\
\hline Face $(\mathbf{N})$ & & & & Radius and ulnar fracture & 6 \\
\hline Nasal bruise/fracture & 11 & Haemato-pneumo-thorax & 1 & Humerus fracture & 1 \\
\hline Injuries of the eye & 21 & Abdomen (N) & & Burns & 2 \\
\hline Fracture of mandible & 1 & Bland abdominal trauma/bruise & 12 & Shoulder injury & 5 \\
\hline Epistaxis & 4 & Genital-Scrotum & 1 & Ankle joint distortion & 1 \\
\hline Laceration & 10 & Pelvic fracture & 5 & & \\
\hline Injuries of the lips/teeth & 17 & Spleen rupture & 3 & & \\
\hline Otorrhea & 3 & Renal laceration & 1 & Total $N=200$ & \\
\hline
\end{tabular}

the percentage of children with additional injuries $(r=0.27 ; \mathrm{p}=0.0001)$ (Figure 2). The distribution of injuries in other parts of the body is presented in Figure 3. Within the individual regions injured, there is a significant difference between the age groups only with respect to the face $(r=0.2 ; p=0.0001)$. However, if the children are compared separately according to age, namely $<7$ years and $\geq 7$ years, the age groups are found to have a significant effect in terms of injuries to the chest, abdomen, extremities and pelvic girdle $(\mathrm{p} \leq 0.05)$. Such injuries occur more often in older children.

\subsection{Injury Severity}

There was a significant correlation between the severity of the head injury and the occurrence of concomitant injuries: mild TBI $18.43 \%$, moderate TBI $46.66 \%$ and severe TBI $71.42 \%(\mathrm{r}=0.19 ; \mathrm{p}=0.046)$. Only in the region of the head and neck $(r=-1 ; p=0.0001)$ and the abdomen $(r=1 ; p=0.0001)$ were there significant correlations between the severity of the head injury and the occurrence of concomitant injuries (Figure 4). The more severe the head injury, the less frequent the occurrence of concomitant injuries to the cervical spine but more frequent the occurrence of abdominal injuries. 


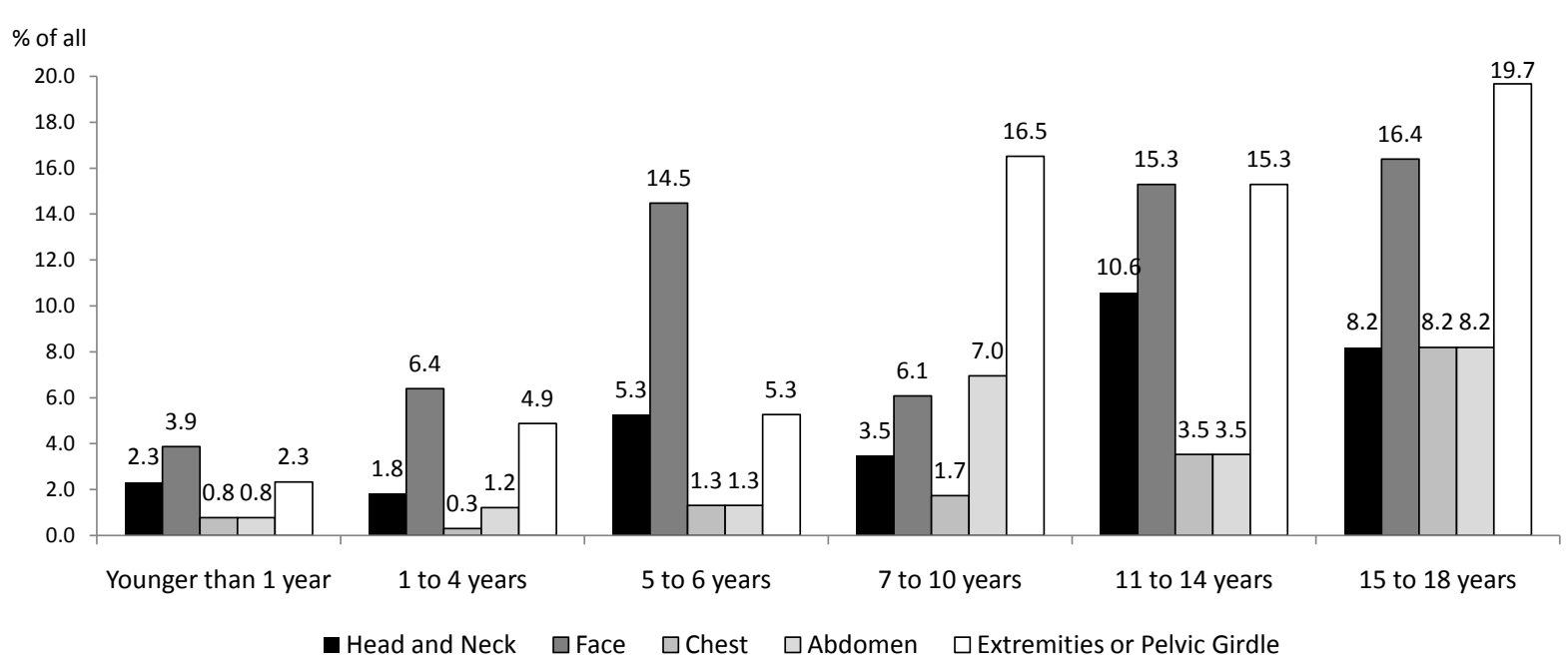

Figure 2. Percentage of children with concomitant injuries, categorised by age group and region of the body $(\mathrm{N}=794)$.

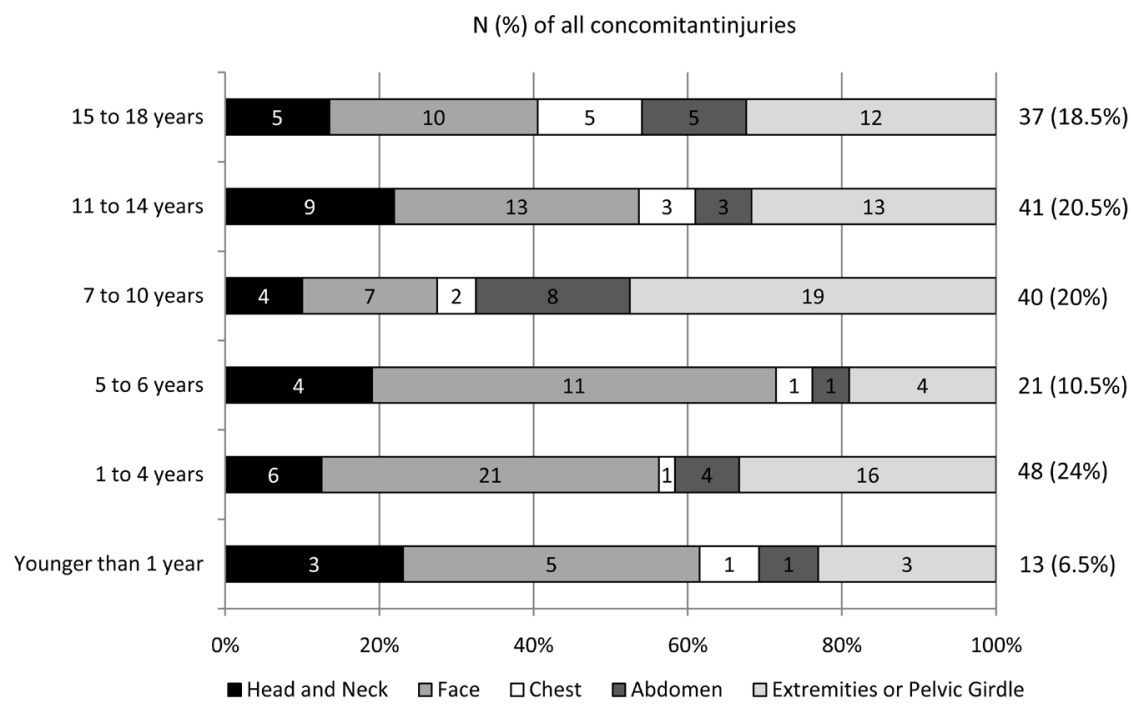

(a)

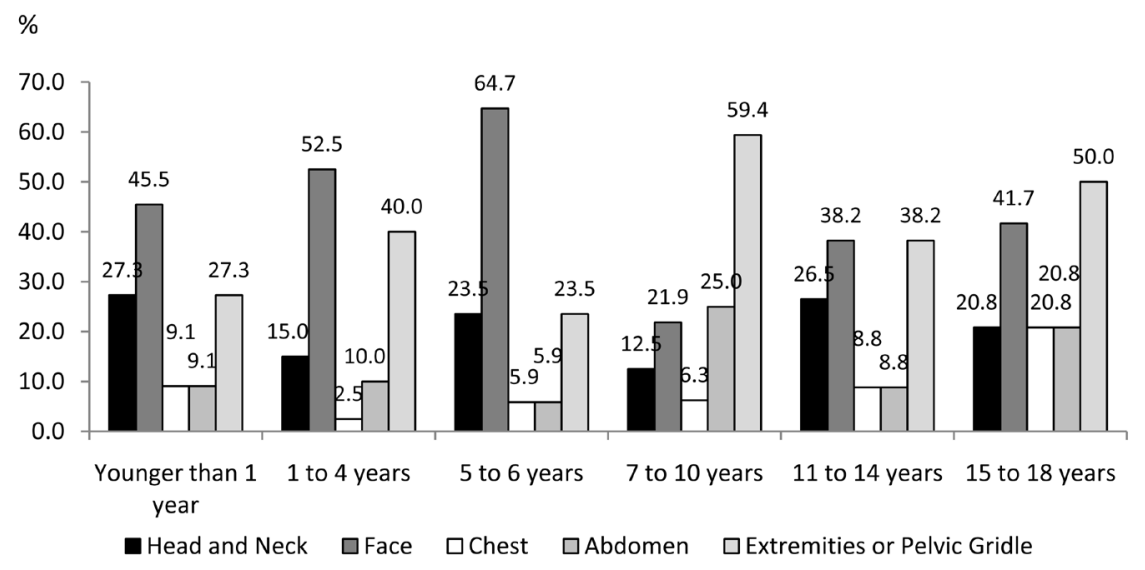

(b)

Figure 3. Distribution of concomitant injuries across the age groups (a) and percentage distribution of the injured regions of the body within one age group (b). The number of concomitant injuries per age group increases as a percentage. 


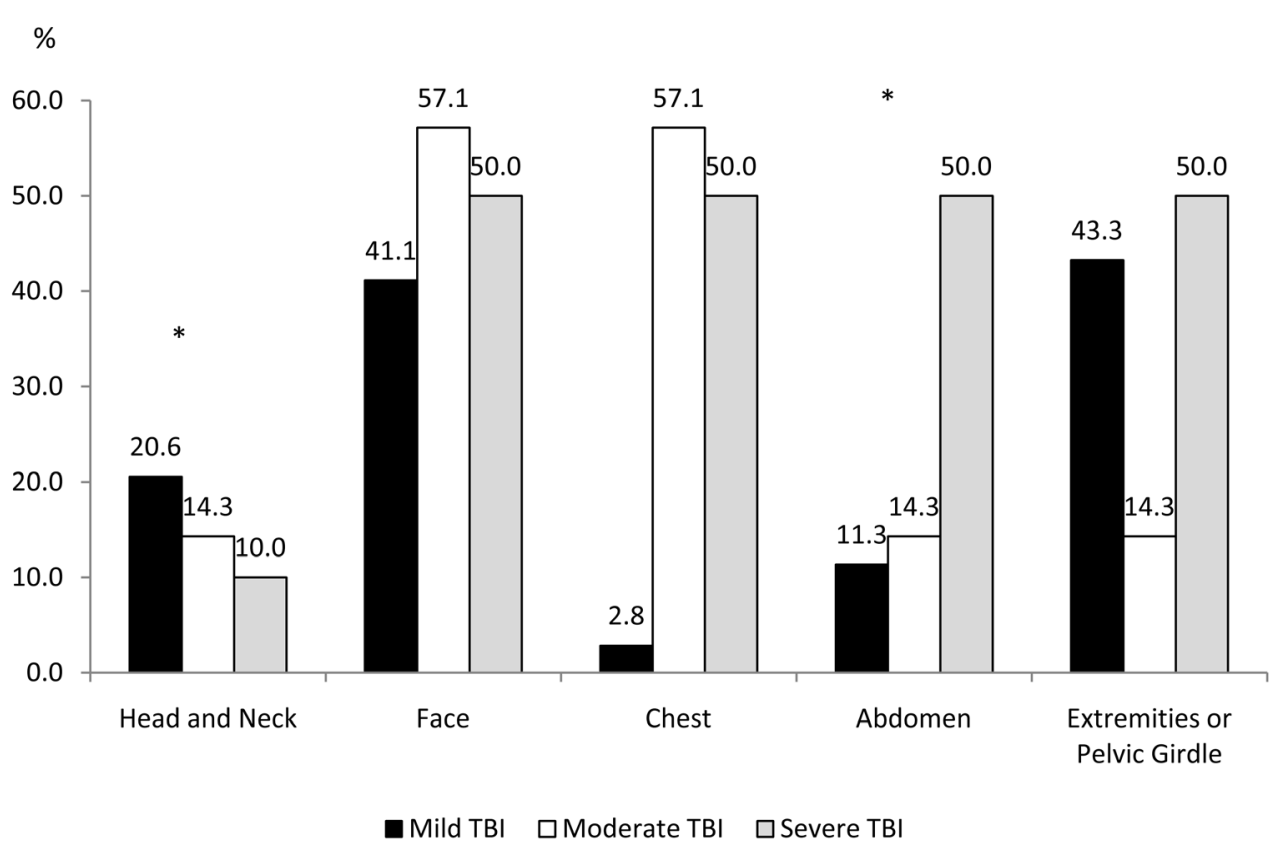

Figure 4. Percentage distribution of concomitant injuries across the three levels of severity of traumatic brain injury in a total of 200 concomitant injuries and 158 children with concomitant injuries (one child can have multiple concomitant injuries in different parts of the body).

\subsection{Trauma Mechanism}

Children with concomitant injuries were found to suffer significantly more falls $(\mathrm{N}=82 ; 51.9 \%)$ than road traffic accidents $(\mathrm{N}=68 ; 43 \%)(\mathrm{p}=0.0001)$. There was no significant difference in the incidence of concomitant injuries to various parts of the body as regards the trauma mechanism, however (Figure 5).

\subsection{Day and Time}

The day of the week did not significantly influence the incidence of concomitant injuries. Whereas the incidence of injuries within one particular region was found to differ significantly on different days $(p \leq 0.019)$, no clear patterns could be discerned. A significant pattern also could not be found when differentiating between workdays and the weekend. There was a significant correlation, albeit rather weak, between the time of admission and incidence of concomitant injuries $(r=0.032 ; \mathrm{p}=0.035)$ (Figure 6). However, the time of admission does not necessarily correlate to the time point of injury.

\subsection{Diagnostic Imaging}

In most children, no $\mathrm{CT}(\mathrm{N}=695 ; 87.5 \%)$ or MRI $(\mathrm{N}=763 ; 96.1 \%)$ examination was performed. A precise breakdown can be found in our previous publication [2]. A positive correlation was found, indicating that the number of CT and MRI scans increases as the incidence of concomitant injuries rises. As opposed to the children with no concomitant injuries, 38 (45.8\%) of those with concomitant injuries had one CT scan, 5 (71.4\%) had 2 CT scans, $3(60 \%)$ had 3 CT scans, and $2(66.7 \%)$ had 4 CT scans $(r=0.27 ; \mathrm{p}=0.043)$.

Compared to the children with no concomitant injuries, $16(53.3 \%)$ of the children with concomitant injuries had one MRI and one (100\%) child 2 MRIs ( $\mathrm{r}=0.17 ; \mathrm{p}=0.046)$.

\subsection{Hospital Stay}

The incidence of concomitant injuries correlated significantly to the length of the children's hospital stay $(r=$ $0.3 ; \mathrm{p}=0.034$ ). On average, children with no concomitant injuries spent 2.5 (SD: 3.1) days in hospital, and those with concomitant injuries 4.5 (SD: 4.9$)$ days $(\mathrm{p}=0.0001)$. The specific localization of a concomitant injury did not significantly influence the hospital stay, however. 


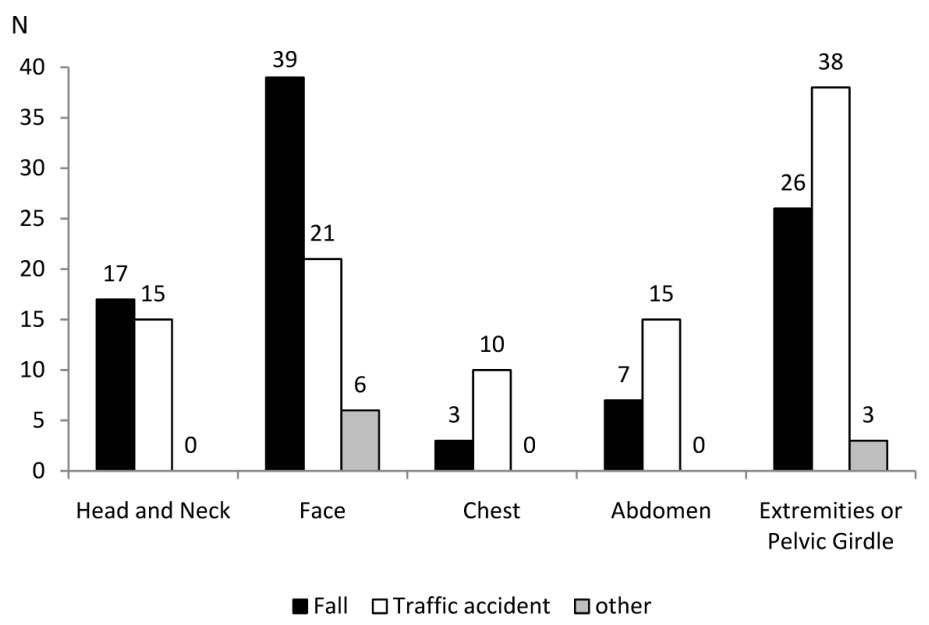

(a)

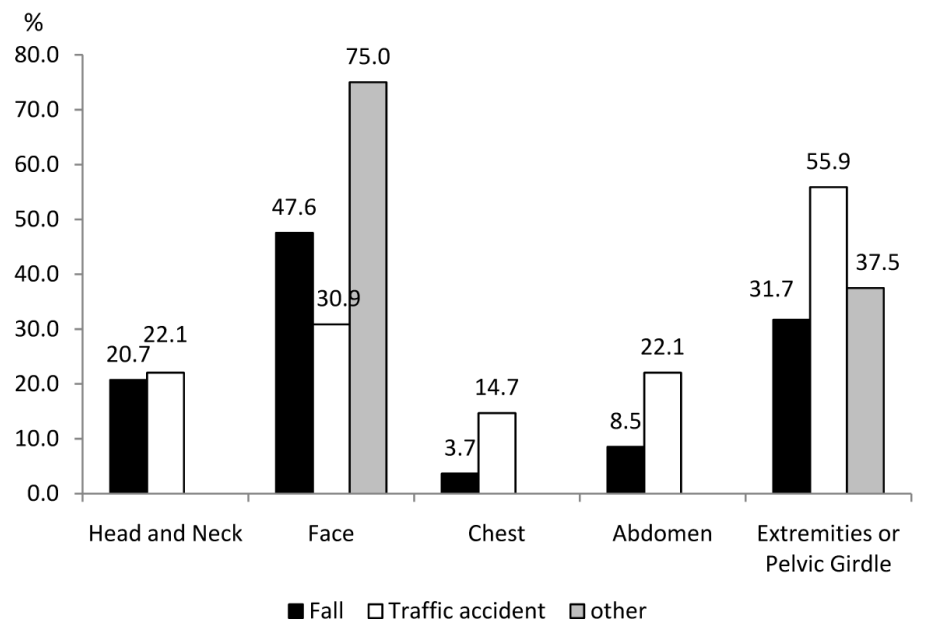

(b)

Figure 5. Incidence of concomitant injuries in regions relative to the trauma mechanism (a), and incidence of concomitant injuries as a percentage of the total of 200 concomitant injuries and 158 children with concomitant injuries (one child can have multiple concomitant injuries in different parts of the body) (b).

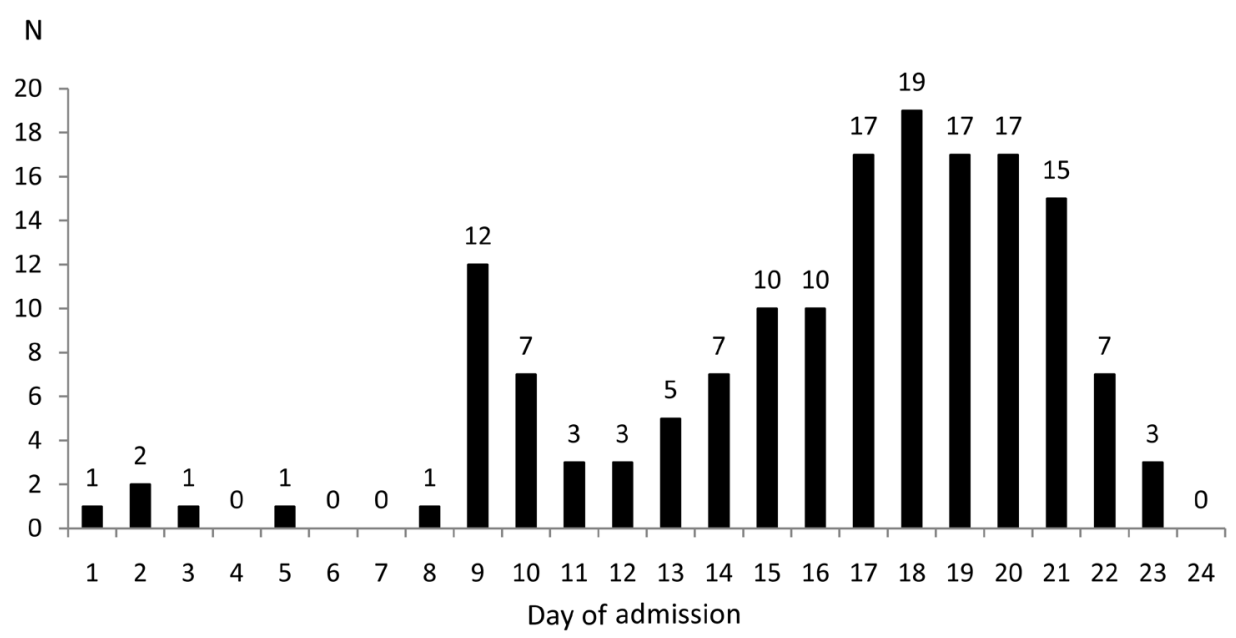

Figure 6. Time of admission of children (N) with concomitant injuries. 


\subsection{Treatment Outcome}

The occurrence of concomitant injuries had a significant impact on the treatment outcome $(\mathrm{p} \leq 0.038)$. Based on the modified Rankin Scale, the incidence of concomitant injuries increased relative to the $\operatorname{score}(r=0.17 ; \mathrm{p}=$ 0.046). The higher the score on the Glasgow Outcome Scale, the more infrequent the concomitant injuries ( $\mathrm{r}=$ $-0.132 ; \mathrm{p}=0.046)$. Hence, outcome deteriorated with concomitant injuries. The modified rankin scale represents a significant difference with better results for children without concomitant injuries: mean score 0.03 to $0.19(\mathrm{p}=0.008)$.

\subsection{Regression Analyses}

A comparison of the importance of different variables revealed that age ( 1 to 6 years) and trauma mechanism (fall) were most influential (Table 4). The most influence according the odds ratio was represented by the age of 5 to 6 years $(\mathrm{OR}=0.373, \mathrm{p}=0.009, \mathrm{CI}=95 \%)$.

\section{Discussion}

Traumatic brain injury is the leading cause of death, morbidity and disability in children and young adults [17]-[19]. It is also the primary cause of death in poly-traumatized children under 12 years of age. The death of a child after sustaining multiple injuries or poly-trauma will more likely result from the traumatic brain injury than from multiple organ dysfunction syndrome or acquired respiratory distress syndrome [1] [20]. The number of children undergoing treatment for traumatic brain injury is rising [21] [22]. Severe TBI is commonly associated with concomitant injuries and plays an important role in clinical management [23]. The involvement of other organ systems typically demands more diagnostic and therapeutic procedures which in turn lead to increased medical, social, psychological and economic costs. It is of great importance to define the age groups that are particularly at risk from severe traumatic and concomitant injuries. An interdisciplinary approach may accelerate recovery and the return to everyday activities. Additionally, the neuropsychological sequelae of TBI in childhood are difficult to estimate and may pose a medical, social and economic burden.

Table 4. Results of the binary logistic regression analysis. Significance was presented by the categories "Mechanism-Fall" and "Age (1 to 4 years and 5 to 6 years)". Highest odds ratio was found for the Category "Age (5 to 6 years)".

\begin{tabular}{|c|c|c|c|c|c|c|}
\hline \multirow{2}{*}{ Categories } & \multirow{2}{*}{ Regression-Coefficient $R$} & \multirow{2}{*}{ Standard error } & \multirow{2}{*}{$\mathbf{p}$} & \multirow{2}{*}{$\begin{array}{l}\text { Odds } \\
\text { Ratio }\end{array}$} & \multicolumn{2}{|c|}{ 95\% Confidence interval for OR } \\
\hline & & & & & Lowest value & Highest value \\
\hline Day & -0.028 & 0.053 & 0.593 & 0.972 & 0.876 & 1.079 \\
\hline Daytime & -0.002 & 0.024 & 0.949 & 0.998 & 0.953 & 1.046 \\
\hline Mechanism(Fall) & -1.895 & 0.245 & 0.001 & 0.150 & 0.093 & 0.243 \\
\hline TBI Severity (Mild) & & & 0.191 & & & \\
\hline TBI Severity (Moderate) & -1.277 & 0.713 & 0.073 & 0.279 & 0.069 & 1.126 \\
\hline TBI Severity (Severe) & -1.023 & 0.947 & 0.280 & 0.360 & 0.056 & 2.302 \\
\hline Age $(0$ to $<1$ year $)$ & & & 0.001 & & & \\
\hline Age (1 to 4 years) & -1.243 & 0.465 & 0.007 & 0.288 & 0.116 & 0.717 \\
\hline Age (5 to 6 years) & -0.986 & 0.378 & 0.009 & 0.373 & 0.178 & 0.783 \\
\hline Age ( 7 to 10 years) & -0.397 & 0.446 & 0.374 & 0.672 & 0.280 & 1.613 \\
\hline Age (11 to 14 years) & -0.204 & 0.408 & 0.617 & 0.816 & 0.367 & 1.814 \\
\hline Age (15 to 18 years) & 0.353 & 0.418 & 0.399 & 1.423 & 0.627 & 3.232 \\
\hline Gender (Female) & 0.237 & 0.214 & 0.270 & 1.267 & 0.832 & 1.929 \\
\hline Absolute Term & 1.955 & 0.864 & 0.024 & 7.063 & & \\
\hline
\end{tabular}




\subsection{Concomitant Injuries and Age}

The majority of the children in our study population were aged between 1 and 4 years, an aspect that could have led to bias in regard to the other age groups. We therefore analyzed the number of patients with concomitant injuries in each age group, revealing that $39 \%$ of the children and young adults between 11 and 18 years sustained concomitant injuries. Older children usually pursue more hazardous leisure activities, and a lack of risk awareness as well as an underestimation of dangerous traffic situations may increase the risk of severe injuries. According to the data published by Maegele et al., the distribution and nature of concomitant injuries in children older than 11 years seem to be congruent with the adult population [24]. Furthermore, the $15-18$ years age group is economically important with respect to the future. Hence, it is essential that morbidity within this age group must be reduced as much as possible. In our study we did not analyze outpatient cases of TBI. In this regard, the number of mild TBIs and the extent of this problem in our society may be underestimated. Furthermore, some adults may underestimate the potential dangers that could result from TBI and thus not seek medical treatment at all.

\subsection{Concomitant Facial Injuries}

Facial injuries were one of the most common concomitant injuries in our study, especially in the patients aged between 1 and 4 years. The development of motor function and coordination conceal the risk of falls on the face without protection. Moreover, the head is proportionally bigger in small children. Our findings confirm those of Schmittenbecher et al., namely that facial injuries are the most common concomitant injuries in children [25]. The number of facial injuries reported was lower (22\%) than ours (33.5\%), however. Head injuries are the most frequent trauma sequelae in infancy and childhood. Consequently, injuries are often also sustained in the face, with concomitant facial injuries reflecting the predominance of head injuries in this age group. An interdisciplinary approach and prompt diagnostic steps may help to improve the continued clinical management and prognosis in young patients. A surgical specialist (e.g. plastic surgeon or ENT surgeon) should therefore always be on hand when caring for children with traumatic brain injury.

\subsection{Concomitant Injuries to the Chest, Extremities and Pelvic Girdle}

High-speed accidents typically lead to traumatic injuries that involve a higher number of organ systems. Following poly-trauma, however, concomitant injuries to the chest, abdomen and pelvis are sustained far more infrequently by children than by adults. If poly-traumatised children also sustain injuries to the chest and abdomen, such injuries pose an increased risk of lethality in the same way as cervical spine injuries [1]. Maegele et al. investigated concomitant injuries in all patients with TBI [24]. More than half of the investigated population suffered concomitant injuries. They reported that $37 \%$ of patients sustained concomitant injuries to the extremities and $24 \%$ sustained thoracic injuries. Furthermore, $20 \%$ of these injuries were considered severe [24]. Our data revealed a lower number of injuries to the extremities $(33.5 \%)$ and chest $(6.5 \%)$. As in our study, Schmittenbacher et al. found injuries to the extremities to be the second most characteristic pattern to accompany TBI $(6.6 \%)[25]$.

A study of the anatomy reveals marked differences between children and adults. The ratio of soft-tissue envelope to bone, as well as flexibility, proves to be a protective factor when it comes to fractures in children. However, if a bone is in fact broken in a child (extremity, rib), the force exerted would have to be enormous. Paediatric phrenoptosis causes displacement of the spleen and liver into the abdomen, unlike in adults [1] [20].

This fact confirms that children exhibit different injury patterns. The proportions of the head in relation to the rest of the body, as well as mechanical and tissue resistance, and elasticity, may influence trauma sequelae.

\subsection{Concomitant Injuries and the Trauma Mechanism}

Falls are still the leading cause of head injuries among young individuals [2]. They commonly result in TBI, particularly in infancy and childhood. Fortunately, less than 3\% of toddlers require treatment for injuries sustained in road traffic accidents. Similar results were published by Schmittenbecher et al. (7.4\%). The percentage of children injured in road traffic accidents increases, however, in the event of poly-trauma [7].

The mechanism of trauma in children reflects socially defined factors and road traffic involvement. Children of up to about 6 years of age become involved in road traffic accidents mainly as passengers or pedestrians. 
Older children aged between 7 and 12 years tend to sustain injuries as cyclists and pedestrians. Only once they are over 17 years of age children do increasingly sustain injuries in motorised vehicles [1] [20]. This aspect emphasizes the importance of campaigns that urge the use of protective measures, such as helmets and educational programmes, particularly in children [25].

Young adults typically sustain a TBI from road traffic accidents $(32.8 \%)$. In line with our results, McKinley et al. report that in $67.57 \%$ of individuals between 0 and 14 years of age falls were the main reason for hospitalized treatment of TBI. In older individuals falls were documented only in $8.4 \%$, and road traffic accidents in more than $14 \%$. McKinley revealed, as do our data, that older patients are particularly at risk of traffic accidents. In addition, this age group is more often susceptible to moderate or severe traumatic brain injury. Children who sustain moderate or severe TBI are particularly at risk of cognitive and behavioral disturbances.

\subsection{Concomitant Injuries and Duration of Hospital Stay}

The number of days spent in hospital is higher in older children, despite the fact that they generally suffer fewer TBIs. This phenomenon underlines the results discussed previously, as well as the number of concomitant injuries in older children and young adults [2]. Longer hospital treatment and the involvement of different organ systems demand a multidisciplinary therapeutic approach. Thus, older children may benefit from treatment in high-volume trauma centres where the medical teams have extensive experience of trauma management. Rapid clinical evaluation, drawing on interdisciplinary knowledge and experience, shortens the bridging time if other therapeutic steps are necessary.

The important step in acute management is to identify young patients in need of acute intervention as soon as possible. By determining the risk factors such as age group, mechanism of injury or apparent concomitant injuries (e.g. skin), it may be easier to identify these patients and enhance the management and course of traumatic brain injuries, and thereby improve the outcome and success of potential therapeutic measures [26].

\subsection{Concomitant Injuries and Diagnostic Measures}

Prompt and adequate medical assessment is crucial. Radiological imaging is part of this concept. The development of CT imaging, in particular, has revolutionized trauma management. In recent decades, however, the increasing negative aspects of this procedure due to radiation exposure have come under scrutiny. Children are especially affected in this regard. Therefore, the simple cranial X-ray has become obsolete. Schmittenbecher et al. reported that $73.8 \%$ of children had X-ray, whereas no cranial X-rays were noted in our study [25]. The number of CT scans correlates with our findings in the same study (13.4\%) and demonstrates the crucial role of CT in trauma management. In moderate and severe TBIs, CT is of utmost importance, particularly if a surgical procedure or other therapeutic intervention is necessary. The mechanism and dynamics of the injury, the Glasgow Coma Score and a suspicion of severe concomitant injuries are factors that dictate the need for computed tomography. On the other hand, patients without a neurological deficit benefit from observation, allowing neuroimaging methods to be reserved for situations in which the neurological status deteriorates [2].

Ultrasound is a safe and fast imaging method that can be very useful for screening children regarding intracranial bleeding under one year of age or skull fracture in older children. Staff must be experienced in its use, but it can be deployed at the bedside without sedation - an aspect that may simplify the logistic set-up and accelerate further diagnostic steps. Emergency ultrasound offers more than $90 \%$ sensitivity and $95 \%$ specificity compared to computed tomography for diagnosis of a cranial fracture [27]. Moreover, it has none of the negative effects of ionising radiation.

Magnetic resonance imaging scans enable safe diagnostic testing, especially if the acute phase of head injury has passed. Moreover, it may be of significant prognostic value, especially in the case of traumatic brain injuries $[28]$.

\subsection{Concomitant Injuries and Outcome}

In most patients the neurological outcome was good, a result that correlates with prevailing mild TBI. However, the limitation of the present study is the fact that early outcome was assessed at discharge and functional impairments tend to increase during the two years following injury. Mild brain injury may impair the memory, concentration or behaviour, and lead to future limitations as a result [29]-[32]. 
Nevertheless, Massagli et al. demonstrated that patients with a good Glasgow Outcome Score at discharge were ten times more likely to experience a good recovery based on late outcome [23]. Nevertheless, the outcome of TBI, particularly in children, is complicated by many factors. One major issue is examining children over time and identifying the sequelae arising from brain injury and the changes that the child may experience as a result of natural ageing. We lack adequate and specific assessments for the outcome after TBI in children that consider the different stages of age and development.

\section{Conclusions}

This study delivers current data on children and young adults having sustained a traumatic brain injury. Typical concomitant injuries were those to the face and extremities. Most young patients with concomitant injuries were observed and treated in hospital for 4, 5 days and the majority achieved a good neurological outcome. Individuals aged between 15 and 18 years in particular are at risk of moderate and severe TBI with concomitant injuries, necessitating a multidisciplinary approach.

In younger children, parents appear to be the key to reducing trauma figures. Preventive programmes and education for families and young parents are of utmost importance if the still very high and rising number of TBIs in children is to be decreased.

\section{Conflict of Interest}

C.R. Wirtz has a consultancy contract without relation to the manuscript under consideration Stryker Craniomaxillofacial (a part of Howmedica Osteonics Corp).

T. Kapapa declares that he has no conflict of interest.

M. Kapapa declares that she has no conflict of interest.

C. Posovszky declares that he has no conflict of interest.

J. Gülke declares that he has no conflict of interest.

R. König declares that he has no conflict of interest.

D. Woischneck declares that he has no conflict of interest.

A. Pala declares that he has no conflict of interest.

\section{Ethical approval}

All procedures performed in studies involving human participants were in accordance with the ethical standards of the institutional and national research committee and with the 1964 Helsinki declaration and its later amendments or comparable ethical standards.

\section{Informed Consent}

According to the local ethic committee that approved this study, informed consent was not necessary.

\section{Funding}

The authors did not receive funding or financial support from any institution and organization or any of the following organizations: National Institutes of Health, Welcome Trust, Howard Hughes Medical Institute.

\section{References}

[1] Remmers, D., Regel, G., Neumann, C., Pape, H.C., Post-Stanke, A. and Tscherne, H. (1998) Das polytraumatisierte Kind. Ein retrospektiver Vergleich zwischen polytraumatisierten Kindern, Jugendlichen und Erwachsenen. Der Unfallchirurg, 101, 388-394. http://dx.doi.org/10.1007/s001130050285

[2] Pal'a, A., Kapapa, M., Posovszky, C., Roderer, G., Konig, R., Woischneck, D., et al. (2015) Head Injury in Children: Has a Change in Circumstances Caused an Increase in Treatment Numbers? Journal of Child Neurology, 30, 11531158. http://dx.doi.org/10.1177/0883073814554655

[3] Thompson, A.K., Bertocci, G., Rice, W. and Pierce, M.C. (2011) Pediatric Short-Distance Household Falls: Biomechanics and Associated Injury Severity. Accident, Analysis and Prevention, 43, 143-150. http://dx.doi.org/10.1016/j.aap.2010.07.020 
[4] Schweiberer, L., Dambe, L.T. and Klapp, F. (1978) Der Chirurg; Zeitschrift fur alle Gebiete der operativen Medizen [Multiple Injuries: Severity and Therapeutic Measures]. Die Mehrfachverletzung: Schweregrad und therapeu- tische Richtlinien, 49, 608-614.

[5] Tscherne, H., Oestern, H.J. and Sturm, J. (1983) Osteosynthesis of Major Fractures in Polytrauma. World Journal of Surgery, 7, 80-87. http://dx.doi.org/10.1007/bf01655915

[6] Auner, B. and Marzi, I. (2014) Der Chirurg; Zeitschrift fur alle Gebiete der operativen Medizen [Pediatric Multiple Trauma]. Polytrauma des Kindes, 85, 451-461.

[7] Buschmann, C., Kuhne, C.A., Losch, C., Nast-Kolb, D. and Ruchholtz, S. (2008) Major Trauma with Multiple Injuries in German Children: A Retrospective Review. Journal of Pediatric Orthopedics, 28, 1-5. http://dx.doi.org/10.1097/bpo.0b013e31815b4d90

[8] Ott, R., Kramer, R., Martus, P., Bussenius-Kammerer, M., Carbon, R. and Rupprecht, H. (2000) Prognostic Value of Trauma Scores in Pediatric Patients with Multiple Injuries. The Journal of Trauma, 49, 729-736. http://dx.doi.org/10.1097/00005373-200010000-00023

[9] Kissoon, N., Dreyer, J. and Walia, M. (1990) Pediatric Trauma: Differences in Pathophysiology, Injury Patterns and Treatment Compared with Adult Trauma. CMAJ: Canadian Medical Association Journal, 142, 27-34.

[10] Kay, R.M. and Skaggs, D.L. (2006) Pediatric Polytrauma Management. Journal of Pediatric Orthopedics, 26, $268-277$. http://dx.doi.org/10.1097/01.bpo.0000194695.75903.99

[11] Teasdale, G. and Jennett, B. (1974) Assessment of Coma and Impaired Consciousness. A Practical Scale. The Lancet, 2, 81-84. http://dx.doi.org/10.1016/S0140-6736(74)91639-0

[12] Jennett, B. and Bond, M. (1975) Assessment of Outcome after Severe Brain Damage. The Lancet, 1, 480-484.

[13] Rankin, J. (1957) Cerebral Vascular Accidents in Patients over the Age of 60. III. Diagnosis and Treatment. Scottish Medical Journal, 2, 254-268.

[14] Rankin, J. (1957) Cerebral Vascular Accidents in Patients over the Age of 60. II. Prognosis. Scottish Medical Journal, 2, 200-215.

[15] Rankin, J. (1957) Cerebral Vascular Accidents in Patients over the Age of 60. I. General Considerations. Scottish Medical Journal, 2, 127-136.

[16] Tay, S.Y., Sloan, E.P., Zun, L. and Zaret, P. (2004) Comparison of the New Injury Severity Score and the Injury Severity Score. The Journal of Trauma, 56, 162-164. http://dx.doi.org/10.1097/01.TA.0000058311.67607.07

[17] Stocchetti, N., Conte, V., Ghisoni, L., Canavesi, K. and Zanaboni, C. (2010) Traumatic Brain Injury in Pediatric Patients. Minerva Anestesiologica, 76, 1052-1059.

[18] Keenan, H.T. and Bratton, S.L. (2006) Epidemiology and Outcomes of Pediatric Traumatic Brain Injury. Developmental Neuroscience, 28, 256-263. http://dx.doi.org/10.1159/000094152

[19] McKinlay, A., Grace, R.C., Horwood, L.J., Fergusson, D.M., Ridder, E.M. and MacFarlane, M.R. (2008) Prevalence of Traumatic Brain Injury among Children, Adolescents and Young Adults: Prospective Evidence from a Birth Cohort. Brain Injury, 22, 175-181. http://dx.doi.org/10.1080/02699050801888824

[20] Gatzka, C., Begemann, P.G., Wolff, A., Zorb, J., Rueger, J.M. and Windolf, J. (2005) Verletzungsmuster und klinischer Verlauf polytraumatisierter Kinder im Vergleich mit Erwachsenen. Eine 11-Jahres-Analyse am Klinikum der Maximalversorgung [Injury Pattern and Clinical Course of Children with Multiple Injuries in Comparison to Adults, Ab 11-Year Analysis at a Clinic of Maximum Utilization]. Der Unfallchirurg, 108, 470-480.

[21] Röhrer, S., Woischneck, D. and Kapapa, T. (2012) Epidemiological Data on Head Trauma: Age and Sex. European Orthopaedics and Traumatology, 3, 127-134. http://dx.doi.org/10.1007/s12570-012-0109-7

[22] Röhrer, S., Woischneck, D., Wirtz, C.R. and Kapapa, T. (2013) Epidemiological Data on Head Trauma in Europe. European Orthopaedics and Traumatology, 4, 41-47. http://dx.doi.org/10.1007/s12570-012-0152-4

[23] Massagli, T.L., Michaud, L.J. and Rivara, F.P. (1996) Association between Injury Indices and Outcome after Severe Traumatic Brain Injury in Children. Archives of Physical Medicine and Rehabilitation, 77, 125-132. http://dx.doi.org/10.1016/S0003-9993(96)90156-2

[24] Maegele, M., Engel, D., Bouillon, B., Lefering, R., Fach, H., Raum, M., et al. (2007) Incidence and Outcome of Traumatic Brain Injury in an Urban Area in Western Europe over 10 Years. European Surgical Research, 39, 372-379. http://dx.doi.org/10.1159/000107097

[25] Schmittenbecher, P.P., Fiedler, A. and Hierl, C. (2001) Epidemiology of Hospital Admitted Traumatic Head Injuries of Children in a Rural District of Germany. Intensivmedizin und Notfallmedizin, 38, 484-489. http://dx.doi.org/10.1007/s003900170046

[26] Ducrocq, S.C., Meyer, P.G., Orliaguet, G.A., Blanot, S., Laurent-Vannier, A., Renier, D., et al. (2006) Epidemiology and Early Predictive Factors of Mortality and Outcome in Children with Traumatic Severe Brain Injury: Experience of a French Pediatric Trauma Center. Pediatric Critical Care Medicine, 7, 461-467. 
http://dx.doi.org/10.1097/01.PCC.0000235245.49129.27

[27] Parri, N., Crosby, B.J., Glass, C., Mannelli, F., Sforzi, I., Schiavone, R., et al. (2013) Ability of Emergency Ultrasonography to Detect Pediatric Skull Fractures: A Prospective, Observational Study. The Journal of Emergency Medicine, 44, 135-141. http://dx.doi.org/10.1016/j.jemermed.2012.02.038

[28] Firsching, R., Woischneck, D., Klein, S., Reissberg, S., Dohring, W. and Peters, B. (2001) Classification of Severe Head Injury Based on Magnetic Resonance Imaging. Acta Neurochirurgica, 143, 263-271. http://dx.doi.org/10.1007/s007010170106

[29] Kapapa, T., Konig, K., Pfister, U., Sasse, M., Woischneck, D., Heissler, H., et al. (2010) Head Trauma in Children, Part 1: Admission, Diagnostics, and Findings. Journal of Child Neurology, 25, 146-156. http://dx.doi.org/10.1177/0883073809332698

[30] Kapapa, T., Konig, K., Pfister, U., Sasse, M., Woischneck, D., Heissler, H., et al. (2010) Head Trauma in Children, Part 2: Course and Discharge with Outcome. Journal of Child Neurology, 25, 274-283. http://dx.doi.org/10.1177/0883073809332699

[31] Kapapa, T., Pfister, U., Konig, K., Sasse, M., Woischneck, D., Heissler, H.E., et al. (2010) Head Trauma in Children, Part 3: Clinical and Psychosocial Outcome after Head Trauma in Children. Journal of Child Neurology, 25, 409-422. http://dx.doi.org/10.1177/0883073809340697

[32] Barlow, K.M., Crawford, S., Stevenson, A., Sandhu, S.S., Belanger, F. and Dewey, D. (2010) Epidemiology of Postconcussion Syndrome in Pediatric Mild Traumatic Brain Injury. Pediatrics, 126, e374-e381.

http://dx.doi.org/10.1542/peds.2009-0925 